\title{
IMPLEMENTING 5S PRINCIPLES ON A MANUFACTURING COMPANY, SPS ENGINEERING: CASE STUDY
}

\author{
Tushar Bendigeri ${ }^{1}$, Byoung Hee You ${ }^{2}$, In-Hyouk Song ${ }^{3}$ \\ ${ }^{I}$ Department of Engineering Technology, Texas State University, TX, U.S.A \\ ${ }^{2}$ Department of Engineering Technology, Texas State University, TX, U.S.A \\ ${ }^{3}$ Department of Engineering Technology, Texas State University, TX, U.S.A
}

\begin{abstract}
SPS Engineering is a manufacturing company established in 1998, which produces engine and transmission mounts, suspension mounts, etc. This study is mainly focused on 5 S implementation to help SPS Engineering reach its expectation. The problems of SPS Engineering were messy tool setting, bad working environment, and inefficient process flow. After implementing 5S principles in SPS Engineering, the average time consuming looking for and retrieving drill bits and end mill bits were reduced by $59.5 \%$ and $49.4 \%$, respectively. The time reduction is the direct result of $5 S$ implementation and allows SPS Engineering to manufacture products more efficiently and productively. SPS Engineering is one step ahead in terms of lean manufacturing company.
\end{abstract}

Keywords: 5S, lean, SPS Engineering, sort, set in order, shine, standardize, sustain

\section{INTRODUCTION}

From the quality management perspective, orderliness and neatness have been cogitated as a measure for incessant enhancement of a company [1] and furthermore as the elements to the onset of this development and more progression in all corporations [2]. As quoted by Benjamin Franklin, it has been regarded a platitude to have "Everything in its place and a place for everything" [3]. Attributed to the global cumulative competition, there exist two key disputes for the managers of any company. Primarily, for receiving a competitive advantage, managers are required to make the best decision and cherry-pick the finest approaches for accomplishing the organizational goals and make the best of the opportunities. Next, knowledge deficiency is an underlying source of being unfamiliar with an appropriate technique to efficaciously mend the performance of a company [4]. The facilitating companies should essentially highlight the production of quality services to be able to maintain their customers' satisfaction and tout their authority for a longer duration [5].

The objective of businesses and companies is to get profitable revenue. In the present day, the international markets comprise of declining profit margins, wherein the profit attained from the right workplace management is obligatory. Consequently, it is unambiguously correlated to the contest of a specific organization with the opponent organization. Therefore, the turnover that is deduced from the waste and by means of the right workplace management is formulated merely by imposing an austere workplace management approach such as $5 \mathrm{~S}$ tools [6]. $5 \mathrm{~S}$ is a Japanese practice presented by Takashi Osada in the 1980s [7]. 5S encompasses five ideologies for transforming the organization into an exceedingly well-organized and a successful one, namely: Seiri, Seiron, Seiso, Seiketsu and Shitsuke, meaning Sort, Set in order, Shine, Standardize, and Sustain, respectively $[4,6,8,9] .5 \mathrm{~S}$ is fundamentally a workplace management approach that aids highly in enhancing the work environment, the abilities of the workforce, and thus their productivity [7,9]. 5S is a tool and signifies the various imperative regulations for providing an efficacious workplace [10,11]. Further, it has been deliberated to reduce the deficiency of time along with the redundant activities [6].

\section{BACKGROUND OF SPS ENGINEERING}

This study is mainly focusing on $5 \mathrm{~S}$ implementation which is related to lean and would help SPS Engineering reach its expectation. SPS Engineering is a manufacturing company established in 1998 located in Mysore City, Karnataka, India. The company has produced turning component units for catering to the needs of automobile industries, such as engine and transmission mounts, suspension mounts, heavy duty parts, sheet metal parts, stay rods etc. SPS Engineering began with 40 workers in 1998. However, the company went through huge loss and had to reduce the number of workers to 10 in 2005. Lack of proper knowledge of management caused the company to face inefficiency in work, no profit margin. The objective of this study is to help SPS Engineering promoted to be a lean company through the implementation of 5S tools: sort, set in order, shine, standardize, and sustain. According to the discussion with the manager of SPS Engineering, the company suffers with following problems: 
(1) Dirty work environment: Usage of coolant is excessive while operating machinery without proper cleaning.

(2) Lack of communication between manager and work crews: Results includes less profit and insufficient time management.

(3) Small number of workers: Not completing projects in time for clients at desired time.

(4) Disorganized tools: Workers waste time to find the tool resulting in delaying project completion.

This study fulfills the application of $5 \mathrm{~S}$ tools in SPS Engineering. The expectation from this project are: 1) to reduce waste, 2) to optimize productivity, 3) to achieve more consistent operational results, 4) to improve company's bottom line by reducing costs, 5) to show overall progress, and 6) to improve the process flow. This research is limited to apply $5 \mathrm{~S}$ tools for only one organization, SPS Engineering. However, the organizations which are willing to solve the issues can employ $5 \mathrm{~S}$ tools to enhance their profit, to eliminate poor environment, and to improve the relationship between employees.

\section{METHODOLOGY}

The implementation of $5 \mathrm{~S}$ is depicted in Figure 1. The purpose of this study is to assist SPS Engineering to enhance process flow with $5 \mathrm{~S}$ strategies by reducing possible wastes and increasing the efficiency of operation so that SPS Engineering can reduce manufacturing costs. SPS Engineering has been operated without knowledge of $5 \mathrm{~S}$ principles. 5S implementation delivers a method to reorganize layout and to develop discipline. The concept of sort helps the company sort items as wanted and unwanted. The required items are kept and the unwanted ones are thrown away or recycled $[12,13]$. For better operations, sort step is used to clean work place. SPS Engineering has multiple places to set tools. SPS Engineering stores broken and unbroken items together without sorting. Using sort step, SPS Engineering observed each inventory place and confirmed wanted, unwanted, good, and broken tools. In addition, SPS Engineering puts samples in a cabinet without ordering. SPS Engineering needs to clean all samples out from the cabinet and to decide if samples should be kept or sent back.

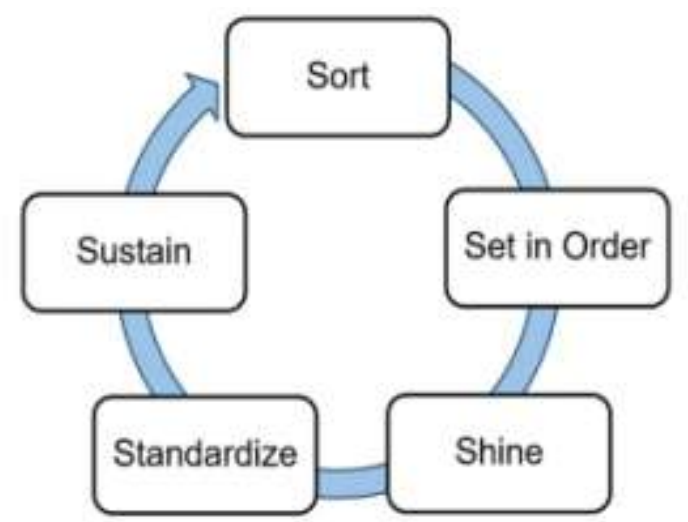

Fig 1: 5S methodology implementation.
Set in order is the path to keep all items properly, which reduces usage of time while picking them for operations. Company should work as per procedure with sort and next set in order. Set in order concept is to place everything separately into right place $[14,15]$. It makes more space. As other manufacturing companies, SPS Engineering has variety of machinery and tools. So, the company needs to make a place to set the tools, to differentiate all sizes, to place each size into distinguished containers, and to attach a label to identify the specific size. The most important step is to educate employees put the items back to the original place so that they can easily get it again next time [16]. The shine concept is related to the creation of a clean work environment. The worker takes responsibility for cleaning after operation. Employees need to clean all tools and sweep and mop the floor to have a clean working environment, and to place all tools back in the right place. The shine step makes longer life time of tools and better working place. SPS Engineering uses massive coolant while operating machine. Hence, the floor easily gets wet and dirty. Manager arouses all employees the importance of the shine step and the danger causing the wet and dirty floor, and requests them to clean the machine and surrounding after and during operation.

Standardization is the way to help the company to set the baseline, which is easy for the new workers to understand and to be familiar with the new structure in the company [17]. It is easy for the old workers to lead the new employees. SPS Engineering manufacturing company does not have any protocols to guide new employee, and it is hard for senior employees to lead them. SPS Engineering needs prepare a list for regulations in the company such as operation rules. The standard helps workers in the company understand how the protocols run. Sustain is the final step for $5 \mathrm{~S}$ implementation. The company prepares a checklist to help the manager to make sure whether employees follows the protocols to sustain [18,19]. The employees know properly the first $4 \mathrm{~S}$ tools and run daily in order without question. Running sort, set in order, shine, and standardize daily means completing sustain. 


\section{RESULTS}

\subsection{Implementation of $5 \mathrm{~S}$}

SPS Engineering used a lot of drills and mills, which were not in order. Based on 5S tools, SPS Engineering sorted and cleaned all items. The broken tools were thrown away so that places for setting the items could have more space. Figure 2 shows the tool box for end mill bits before (Figure 2 (a)) and after (Figure 2 (b)) applying sort and set in order
Sort concept. After the broken items sorted out, mill bits were rearranged. It helped SPS Engineering shortens time to look for the items. Even though it took a time to rearrange tools, it enabled to reduce searching time. After implementation, all staff in the company clearly understood what $5 \mathrm{~S}$ tools is and how it works. Managers made a list to help employees in the company to know what and when they should do $5 \mathrm{~S}$ activities. Table 1 is the draft of checking each step of the $5 \mathrm{~S}$.

Table 1: Standardization (everyday protocols for the operators)

\begin{tabular}{|c|ll|l|}
\hline 5S & \multicolumn{1}{|c|}{ Order } & Operator \\
\hline Sort & $\bullet$ & $\begin{array}{l}\text { Make sure all broken stuff (samples, drills, mills etc.) are thrown away. } \\
\text { Make sure inventory room or place are for good tools. } \\
\text { No good (new parts) or bad stuff (broken items) are together. }\end{array}$ & Staff (random) \\
\hline Set in order & $\bullet \quad \begin{array}{l}\text { Check all tools in the right place (tools in the cabinet, moving } \\
\text { machines in the marked area) especially drills and mills. }\end{array}$ & Staff (random) \\
\hline Shine & $\bullet$ & $\begin{array}{l}\text { Clean the machines, surroundings. } \\
\text { Sweep the floor and wipe it with a mop. }\end{array}$ & Staff (random) \\
\hline Standardize & $\bullet \quad$ Make sure everyone is following the protocol made after 5S. & Staff (random) \\
\hline Sustain & $\bullet \quad$ Keep everyone use 5S everyday & plant manager \\
\hline
\end{tabular}

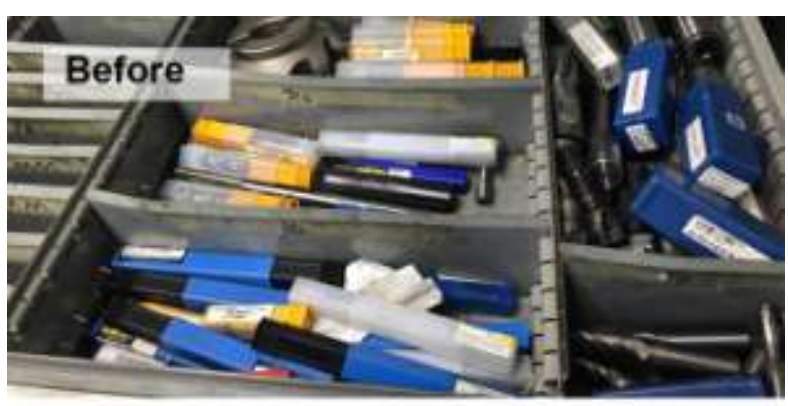

(a)

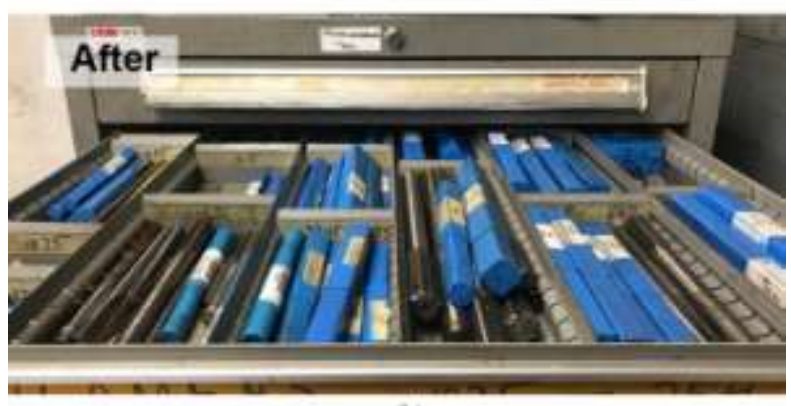

(b)

Fig 2: (a) Not sorted end mill bits. (b) Arranged end mill bits applying sort and set in order concepts.

\subsection{Assessment Rubric Criteria}

It was necessary to know the effect of $5 \mathrm{~S}$ tools before and after implementing with 5S score. Production 5S checksheet was obtained from Lean Enterprise Institute, Inc., which consists of five sections: sort, set in order, shine, standardize and sustain [20]. 
Table 2: The evaluation of Production of 5S Checksheet

\begin{tabular}{|c|c|c|c|c|c|c|c|c|c|c|c|}
\hline \multirow[t]{2}{*}{$\#$} & \multirow[t]{2}{*}{ Item } & \multicolumn{2}{|c|}{ Sort } & \multicolumn{2}{|c|}{ Set in order } & \multicolumn{2}{|c|}{ Shine } & \multicolumn{2}{|c|}{ Standardize } & \multicolumn{2}{|c|}{ Sustain } \\
\hline & & Before & After & Before & After & Before & After & Before & After & Before & After \\
\hline 1 & $\mathrm{H} \& \mathrm{~S}$ & 1 & 3 & 0 & 2 & 2 & 3 & 1 & 2 & 1 & 4 \\
\hline 2 & Environmental & 2 & 2 & 0 & 3 & 1 & 2 & 1 & 2 & 1 & 2 \\
\hline 3 & Facilities & 1 & 2 & 1 & 2 & 2 & 3 & 2 & 3 & 0 & 4 \\
\hline 4 & Floors \& Gangways & 2 & 3 & 0 & 2 & 1 & 2 & 1 & 2 & 1 & 4 \\
\hline 5 & Duty Technician & 0 & 2 & 0 & 3 & 1 & 2 & 2 & 3 & 1 & 3 \\
\hline 6 & Tooling, Fixtures, Jigs & 3 & 3 & 1 & 2 & 2 & 2 & 0 & 1 & 0 & 3 \\
\hline 7 & Wires, cabling \& Hoses & 1 & 1 & 1 & 1 & 1 & 2 & 1 & 2 & 1 & 3 \\
\hline 8 & Workbenches \& surfaces & 2 & 2 & 1 & 3 & 2 & 3 & 0 & 2 & 2 & 2 \\
\hline 9 & Visual tracking boards & 0 & 1 & 1 & 2 & 1 & 3 & 3 & 3 & 2 & 2 \\
\hline 10 & Red Tag & 0 & 1 & 0 & 1 & 2 & 3 & 0 & 2 & 0 & 3 \\
\hline 11 & Mobile Equipment & 3 & 3 & 1 & 3 & 1 & 2 & 2 & 2 & 1 & 3 \\
\hline 12 & Storage & 1 & 1 & 0 & 2 & 1 & 2 & 3 & 3 & 0 & 4 \\
\hline 13 & Cleaning Standards & 2 & 3 & 1 & 3 & 1 & 2 & 1 & 2 & 1 & 4 \\
\hline 14 & Machine Guards, Windows \& Interlocks & 1 & 1 & 1 & 3 & 2 & 3 & 0 & 2 & 0 & 2 \\
\hline & Subtotal & 19 & 28 & 8 & 31 & 20 & 34 & 17 & 31 & 11 & 43 \\
\hline
\end{tabular}

Table 3: 5S scores before and after applying 5S tools from Production of 5S Checksheet

\begin{tabular}{|c|c|c|c|}
\hline$\#$ & \multirow{2}{*}{ Item } & \multicolumn{2}{|c|}{ Score } \\
\cline { 3 - 4 } & & Before & After \\
\hline 1 & H \& S & 5 & 14 \\
\hline 2 & Environmental & 5 & 11 \\
\hline 3 & Facilities & 6 & 14 \\
\hline 4 & Floors \& Gangways & 5 & 13 \\
\hline 5 & Duty Technician & 4 & 13 \\
\hline 6 & Tooling, Fixtures, Jigs & 6 & 11 \\
\hline 7 & Wires , cabling \& Hoses & 5 & 9 \\
\hline 8 & Workbenches \& surfaces & 7 & 12 \\
\hline 9 & Visual tracking boards & 7 & 11 \\
\hline 10 & Red Tag & 2 & 10 \\
\hline 11 & Mobile Equipment & 8 & 13 \\
\hline 12 & Storage & 5 & 11 \\
\hline 13 & Cleaning Standards & 6 & 14 \\
\hline 14 & Machine guards, windows \& & 4 & 11 \\
& interlocks & & \\
\hline & Grand totals & $75 / 280$ & $167 / 280$ \\
\hline & 5S Score & 1.3 & 2.9 \\
\hline
\end{tabular}

The evaluation with the statements of production $5 \mathrm{~S}$ checksheet uses the scale, 0 - very bad, 1 - bad, 2 - OK, 3 good, 4 - very good. To calculate $5 \mathrm{~S}$ score; (1) add up each column, (2) add each column together to get total, (3) divide total by 280 , and (4) multiply this score by 5 . It gives $5 \mathrm{~S}$ score. The manager of SPS Engineering carefully audited and marked the checksheet. Table 2 shows the evaluation results before and after applying $5 \mathrm{~S}$ implementation. Here, $\mathrm{B}$ and $\mathrm{A}$ stand for before and after $5 \mathrm{~S}$ implementation, respectively. The advantage of the evaluation using the checksheet is to help diagnose the weakness, which needs to be improved. As seen in Table 3, the weakest columns were set in order and sustain before implementing 5S. However, these sections were most improved by applying $5 \mathrm{~S}$ tools of $388 \%$ and $390 \%$ for set in order and sustain, respectively. Table 3 shows the total scores of individual items of the checksheet and the $5 \mathrm{~S}$ scores before and after applying $5 \mathrm{~S}$ tools. The $5 \mathrm{~S}$ score was $1.3 / 5$ before implementation, which was improved to $2.9 / 5$. 


\subsection{Time Analysis}

The data was collected by recording the time required to get six different sizes of drill bits and seven different sizes of end mill bits before and after $5 \mathrm{~S}$ implementation to evaluate the efficiency. Eight technicians for drill bits and five technicians for the mill bits were involved for this evaluation. The data were averaged of three cycles for individuals. The results are shown in Figure 3 and Figure 4 before and after implementing 5S. All staffs spent longer time to find the tools before $5 \mathrm{~S}$ implementation. The average times, however, looking for drill bits and end mill bits were reduced by $59.5 \%$ and $49.4 \%$, respectively due to the $5 \mathrm{~S}$ implementation. The time-saving enables to promote the productivity and to lower defect rate.

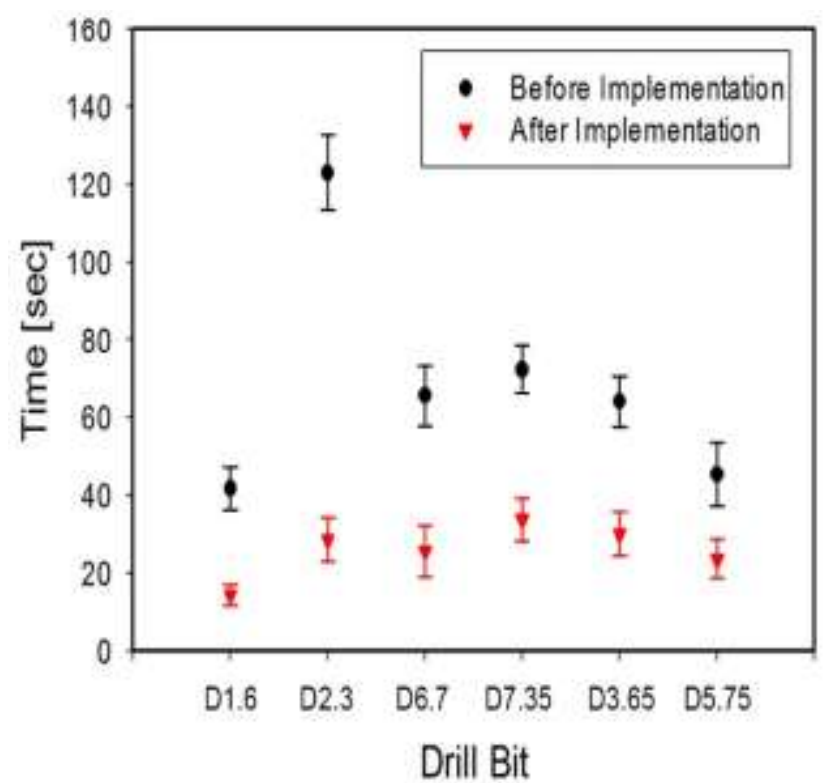

Fig 3: The average time consuming in looking for drill bits before and after $5 \mathrm{~S}$.

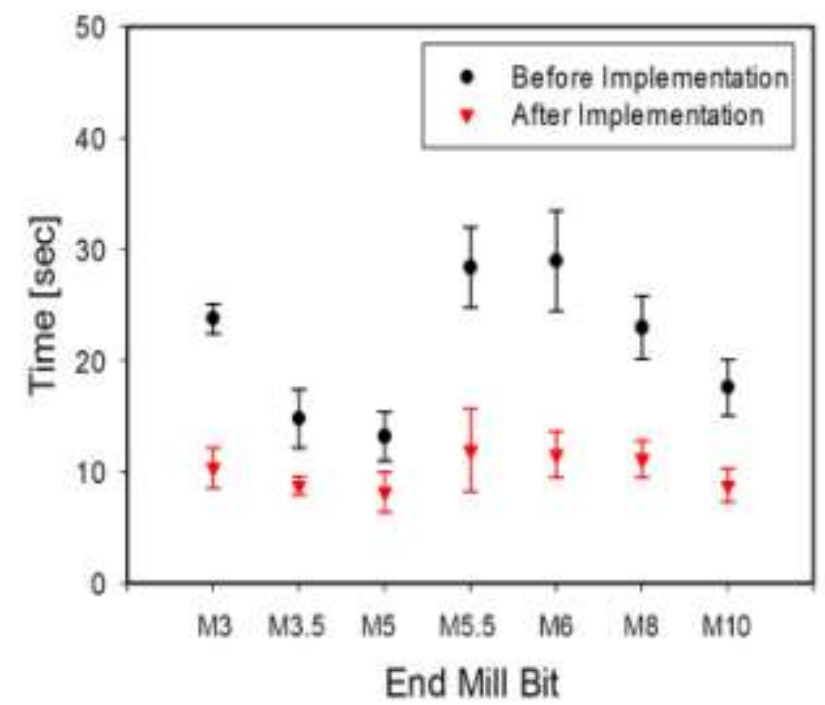

Fig 4: The average time consuming in looking for end mill bits before and after $5 \mathrm{~S}$.

\section{CONCLUSION}

SPS Engineering uses a lot of hand controlled machines such as CNC machines requiring coolant and producing scraps. Hence, the working environment is easily wet and dirty. SPS Engineering decided to implement $5 \mathrm{~S}$ to make workplace more organized and to raise the efficiency of production. The results show enhancement of work environment and reduction of time deficiency due to the implementation of 5S. Most of all, employees have the proper knowledge of $5 \mathrm{~S}$ concept. Now, the manager in the company requires all employees to keep the concept in mind and to do $5 \mathrm{~S}$ for efficient process flow. SPS Engineering should use $5 \mathrm{~S}$ as daily routine, which is the key to make employees in the company feel better and be willing to contribute their energy to promote company's image. Even if the simple rearrangement of workplace is not enough, this is the first step for SPS Engineering to be a lean manufacturing company.

\section{REFERENCES}

[1] Yusof, S.M. and Aspinwall, E. (2001). Case studies on the implementation of TQM in the UK automotive SMEs. International Journal of Quality \& Reliability Management, 18, 722-7.

[2] Ho, S.K.M. (1999). 5-S practice: the first step towards total quality management. Total Quality Management, $\quad 10, \quad 345-356$. http://dx.doi.org/10.1080/0954412997875.

[3] Uma, D.S. and Kannan, A. (2010). Implementation of $5 \mathrm{~s}$ in HRM. Journal of Contemporary Research in Management, 5, 1-6.

[4] Rai, P. (2016). Effectiveness of 5S Implementation on Organizations Performance. International Monthly Refereed Journal of Research in Management \& Technology, 5, 1-10.

[5] Gürel, D.A. (2013). A Conceptual Evaluation of 5S Model in Hotels. African Journal of Business Management, 7, 3035-3042. http://dx.doi.org/10.5897/AJBM2013.7098.

[6] Deshpande, P.S., Damle, V.V., Patel, M.L., Kholamkar, A.B. (2015). Implementation of ' $5 \mathrm{~S}$ ' Technique in a Manufacturing Organization: A Case Study. International Journal of Research in Engineering and Technology, 4, 136-148.

[7] Ab Rahman, M.N., Khamis, N.K., Zain, R.M., and Mahmood, W.H.W. (2010). Implementation of 5S practices in The Manufacturing Companies: A case study. American Journal of Applied Science, 7, 11821189. http://dx.doi.org/10.3844/ajassp.2010.1182.1189.

[8] Shaikh, S., Alam, A.N., Ahmed, K.N., Ishtiyak, S., Hasan, S.Z. (2015). Review of 5S Technique. International Journal of Science, Engineering and Technology Research (IJSETR), 4, 927-931.

[9] Yadav, Y., Yadav, G., Chauhan, S. (2010). Implementation of $5 \mathrm{~S}$ in Banks. International Journal of Research in Commerce, Economics \& Management, 1, 1245-1249. 
[10] Ablanedo-Rosas, J.H., Alidaee, B., Moreno J.C., and Urbina, J. (2010). Quality improvement supported by the 5S, an empirical case study of Mexican organizations. International Journal of Production Research, 48, 7063-7087. http://dx.doi.org/10.1080/00207540903382865.

[11] Kakkar, V., Dalal, V.S., Choraria, V., Pareta, A.S., and Bhatia, A. (2015). Implementation of 5S Quality Tool In Manufacturing Company: A Case Study. International Journal of Scientific \& Technology Research, 4, 208-213.

[12] Korkut, D.S., Cakicier, N., Erdinler, E.S., Ulay G., and Dogan, A.M. (2009). 5S activities and its application at a sample company. African Journal of Biotechnology, 8, 1720-1728.

[13] Michalska, J., Szewieczek, D. (2007). The 5S Methodology as a Tool for Improving the Organization. Journal of Achievement in Material and Manufacturing Engineering, 24, 211- 215.

[14] Khedkar, S.B., Thakre, R.D., Mahantare, Y.V., Gondne, R. (2012). Study of Implementing 5S Techniques in Plastic Moulding. International Journal of Modern Engineering Research, 5, 36533656.

[15] Rojasra, P.M., Qureshi, M.N., (2013). Performance Improvement through 5S in Small Scale Industry: A case study. International Journal of Modern Engineering Research, 3, 1654-1660.

[16] Lingareddy, H., Reddy, G.S., Jagadesh, K. (2013). 5S as a tool and strategy for improving the work place. International Journal of Advanced Engineering Technology, 4, 28-30.

[17] Dulhai, G. (2008). The 5S strategy for continuous improvement of the manufacturing process in auto car exhaust. Journal of Management \& Marketing, 3, 115-120.

[18] Bullington, K.E. (2003). 5S for suppliers. Quality Progress, 36(1), 56-59.

[19] Maggie, L.Y. (2006). Library as place: implementation of 5S system. Journal of East Asian Libraries, 139, 57-67.

[20] Lean Enterprise Institute, http://www.lean.org. 